\title{
Heat transfer coefficient determination using the FEM with time-dependent Trefftz-type basis functions in subcooled flow boiling in a minichannel
}

\author{
Beata Maciejewska ${ }^{1, *}$, and Magdalena Piasecka ${ }^{2}$ \\ ${ }^{1}$ Faculty of Management and Computer Modelling, \\ ${ }^{2}$ Faculty of Mechatronics and Mechanical Engineering, \\ Kielce University of Technology, Al. Tysiaclecia Panstwa Polskiego 7, 25-314 Kielce, Poland
}

\begin{abstract}
Results concerning flow boiling heat transfer in a vertical minichannel of $1.7 \mathrm{~mm}$ depth were shown. The channel was asymmetrically heated by a thin foil. Its surface temperature was recorded continuously in points by thermocouples. Measurements were carried out in $0.01 \mathrm{~s}$ intervals. The objective of the numerical calculations was to determine the heat transfer coefficient on the heated foil-fluid contact surface in the minichannel from the Robin boundary condition. Both the foil and fluid temperatures were the result of solving the nonstationary two-dimensional problem in the foil and flowing fluid. The problem was solved by using the FEM combined with Trefftz-type basis functions. The values of the time-dependent local heat transfer coefficient were presented and discussed.
\end{abstract}

\section{Introduction}

Miniaturization of devices is being progressively applied in cooling technologies designed to prevent exceeding operating temperatures. A compact heat exchanger responds to the issues of transfer in confined spaces in which conventional size channels cannot be used. Extensive efforts to recognize boiling phenomena in minichannels include theoretical analyses based on experimental measurements. The results can be applied to the construction of compact heat exchangers and using them in heating, cooling and thermoregulation applications.

In order to estimate the intensity of heat transfer accompanying flow boiling in a mini heat exchanger device, the main experimental data are needed for the heat transfer coefficient identification: the heated wall temperature, the temperature gradient and the temperature of the fluid flowing along a minichannel. These quantities were obtained by solving the inverse problem [1] in the heated wall and in the flowing fluid. The method proposed by Trefftz [2] can be used to solve the inverse problems. This approach is based on an approximation of the unknown solution by a linear combination of functions that exactly satisfy the differential equation.

Details of the method based on the Trefftz functions can be found in [3]-[12]. In this work, to solve the nonstationary two-dimensional problem in the flowing fluid the time-dependent Trefftz functions for the FourierKirchhoff equation were determined. These functions were used to construct the nonstationary FEM basis functions.

\section{Experiment}

The test section with two parallel minichannels (Fig. 1) is the main element of flow loop realized in the experimental stand, which view is shown in Fig. 2.

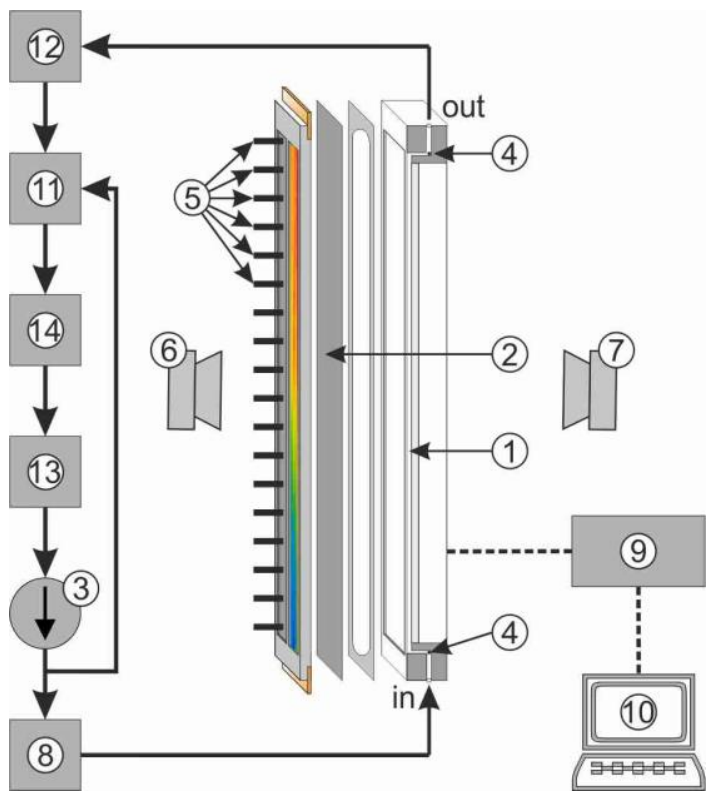

Fig. 1. The main elements of the experimental stand: 1 - a minichannel, 2 - a heated foil, 3 - a gear pump; 4,5 - thermocouples, 6 - an infrared camera, 7 - a high speed camera, 8 - a Coriolis mass flow meter, 9 - data acquisition stations, 10 - a pc computer, 11 - a compensating tank/ a pressure regulator, 12 - a heat exchanger, 13 - a filter, 14 - a deaerator.

\footnotetext{
Corresponding author: beatam@tu.kielce.pl
} 


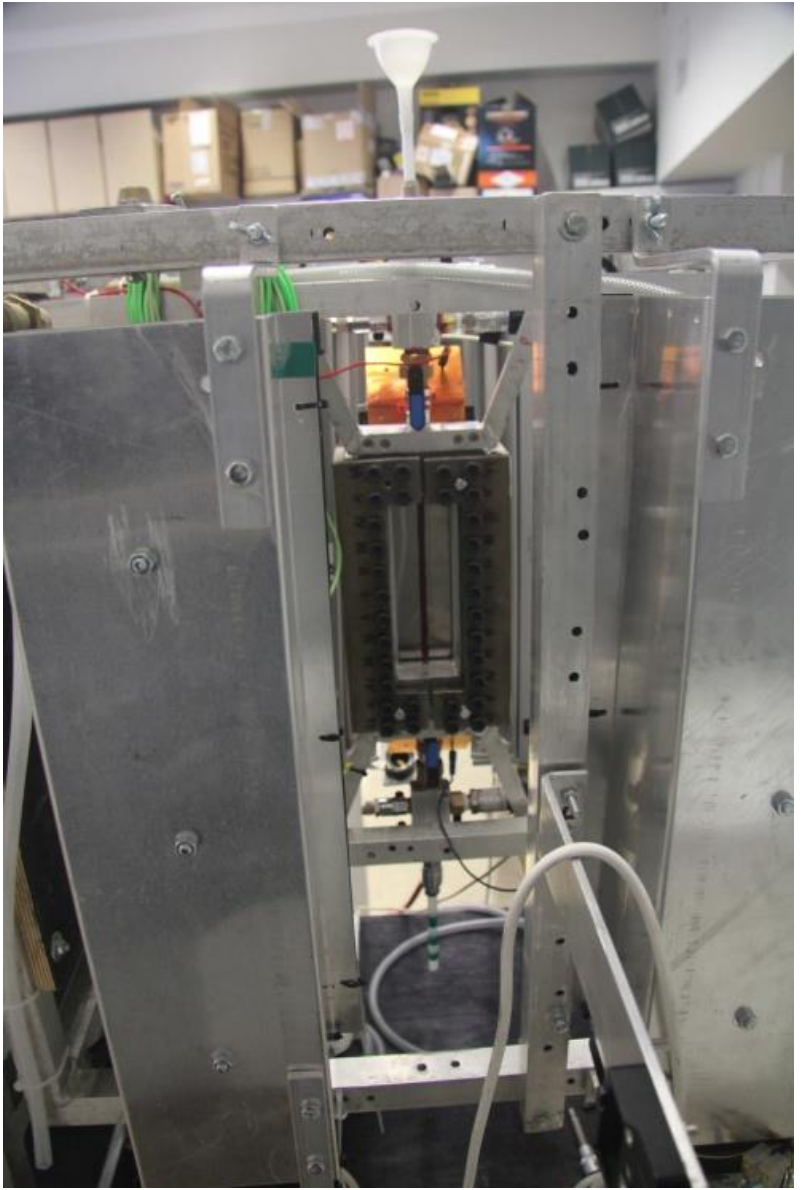

Fig. 2. The view of the experimental stand.

The components of the test section are two $26.5 \mathrm{~mm}$ wide, $180 \mathrm{~mm}$ long and $1.7 \mathrm{~mm}$ deep minichannels (1). A $0.1 \mathrm{~mm}$ thick foil (2), made of Haynes-230 alloy is heated while FC-72 Fluorinert flowing along the minichannels thanks to the gear pump (3). In the selected minichannel temperature of the outer side of the foil is measured with 18 points by K-type thermocouples (5). Two other thermocouples control fluid temperature at the inlet and outlet of the minichannels (4). Foil temperature of the second minichannel is monitored by an infrared camera (6). The opposite surface of the heated foil is observed through the glass using highspeed camera (7), simultaneously. A mass flow meter (8) is used to control the fluid flow in the flow loop. Pressure at the minichannel inlet and outlet, current supplied to the foil and voltage drop across a foil were also monitored continuously.

The supply and control system contains: an inverter welder, a shunt, an ammeter and a voltmeter. The data acquisition system consists of two data acquisition stations (9) and a computer (10) with a appropriate software.

During an experiment series, there was a gradual increase in the electric power supplied to the foil. All measurements were carried out in $0.01 \mathrm{~s}$ intervals.

\section{Analysis and modelling}

The objective of the numerical calculations, refer to an experiment, was to determine the heat transfer coefficient during FC-72 flow boiling in a minichannel from the Robin boundary condition:

$$
\alpha(x, t)=\frac{-\lambda_{F} \frac{\partial T_{F}\left(x, \delta_{F}, t\right)}{\partial y}}{T_{F}\left(x, \delta_{F}, t\right)-T_{f}\left(x, \delta_{F}+\delta_{T}, t\right)}
$$

where $\lambda_{F}-$ the thermal conductivity coefficient of the foil, $\delta_{F}-$ the foil thickness, $T_{F}-$ the foil temperature, $T_{f}-$ the fluid temperature, $\delta_{T}-$ the thickness of the thermal boundary layer, $x$ - the spatial variable referred to the flow direction, $y$ - the spatial variable referred to the direction perpendicular to the flow direction (referring to the thickness of the heated foil).

Both the foil and fluid temperatures were the result of solving the inverse nonstationary two-dimensional problem in two neighboring domains: the heated foil and flowing fluid. It was assumed that nonstationary temperature distribution in the heated foil $(x, y) \in \Omega_{F}$ for $t>0$ was described by the heat equation

$$
\nabla^{2} T_{F}-\frac{\rho_{F} c_{p_{-} F}}{\lambda_{F}} \frac{\partial T_{F}}{\partial t}=-\frac{I \cdot \Delta U}{A \cdot \delta_{F} \cdot \lambda_{F}}
$$

whereas in the thermal boundary layer of fluid $\left((x, y) \in \Omega_{T}\right)$ for $t>0$ by the Fourier-Kirchhoff equation

$$
\nabla^{2} T_{f}-w_{x}(y) \frac{\partial T_{f}}{\partial x}-\frac{\rho_{f} c_{p_{-} f}}{\lambda_{f}} \frac{\partial T_{f}}{\partial t}=0
$$

The boundary conditions have the form:

$$
\begin{gathered}
T_{f}(x, y, 0)=T_{0_{-} f}(x, y) \\
T_{F}(x, y, 0)=T_{0_{-} F}(x, y) \\
=T_{p}\left(t_{k}\right) \text { for } p=1,2, \ldots, P, \\
\frac{\partial T_{F}}{\partial x}(0, y, t)=0 \\
\frac{\partial T_{F}}{\partial x}(L, y, t)=0 \\
\lambda_{F} \frac{\partial T_{F}}{\partial y}(x, 0, t)=q_{\text {loss }}(t) \\
T_{f}\left(x, \delta_{F}, t\right)=T_{F}\left(x, \delta_{F}, t\right) \\
T_{f}(0, y, t)=T_{f}^{\text {in }}(t) \\
T_{f}(L, y, t)=T_{f}^{\text {out }}(t)
\end{gathered}
$$$$
T_{F}\left(x_{p}, 0, t_{k}\right)=T_{p}\left(t_{k}\right) \text { for } p=1,2, \ldots, P, k=1,2, \ldots K
$$ 
where $\Omega_{F}=\left\{(x, y) \in R^{2}: 0<x<L, \quad 0<y<\delta_{F}\right\}$, $\Omega_{T}=\left\{(x, y) \in R^{2}: 0<x<L, \quad \delta_{F}<y<\delta_{F}+\delta_{T}\right\}, L$ - the minichannel length, $I$ - the electrical current, $\Delta U$ - the voltage drop, $A$ - the surface area of the heated foil, $P$ - the number of measurements, $K$ - the number of time intervals, $T_{p}-$ the foil temperature measured by thermocouples at the boundary $y=0, q_{\text {loss }}$ - the heat loss to the surroundings [13], $w_{x}$ - component of vector fluid velocity parallel to the minichannel heated surface [14], $\rho_{F}, \quad \rho_{f}-$ the density of the foil and fluid, respectively, $c_{p_{-} F}, c_{p_{-} f}-$ specific heat of the foil and fluid, respectively, $\lambda_{F}, \delta_{F}, \delta_{T}$ - defined as for Eq. (1). The boundary conditions are shown in Fig. 3 .

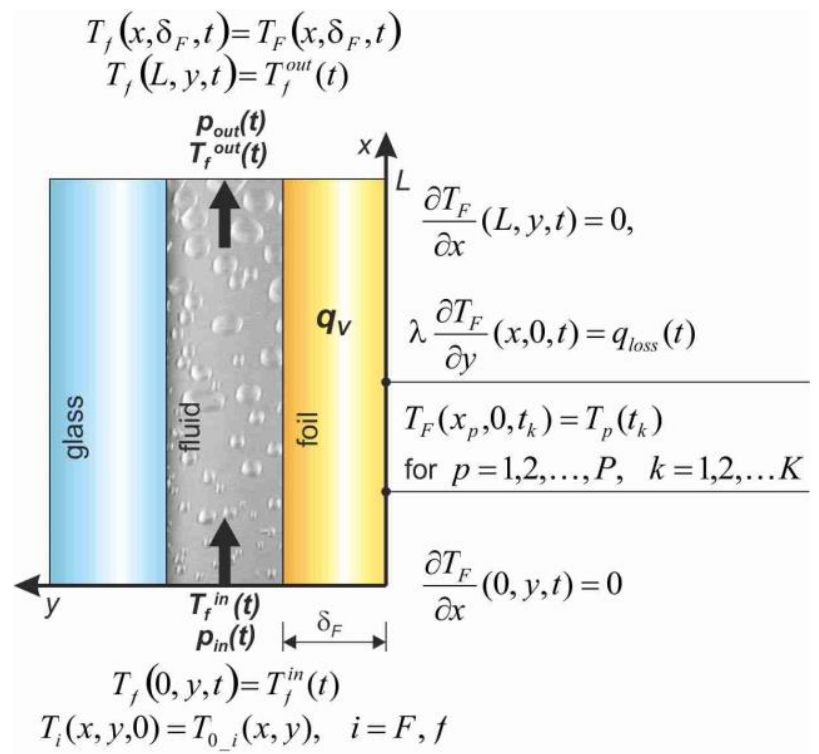

Fig. 3. Boundary conditions.

The solution method of Eqs. (2-3) presented in this article is based on an approach described in [15] concerning to the one-dimensional heat equation.

The problem described in Eqs. (3), (4), (10), (11) and (12) in the thermal boundary layer of fluid $\Omega_{T}$ was solved in the time subintervals by means of the FEM with time-dependent basis functions. This base functions are a linear combinations of Trefftz functions, strictly satisfying the governing equation, and have the following properties in nodes:

$$
f_{j k}\left(x_{i}, y_{i}, t_{i}\right)=\delta_{k i}, i=1,2, \ldots, l w
$$

where $\delta_{k i}$ - the Kronecker delta, $j$ - the element number, $k$ - the basis function number in the $j$-th element, $l w$ - number of nodes in the $j$-th element.

The Trefftz functions are coefficients at partial derivatives in expansion of the differential equation solution in the Taylor series, in which the derivative $\frac{\partial^{2} T_{f}}{\partial y^{2}}$ is replaced by the formula resulting from the Fourier-Kirchhoff equation:

$$
\frac{\partial^{2} T_{f}}{\partial y^{2}}=w_{x}(y) \frac{\partial T_{f}}{\partial x}+\frac{\rho_{f} c_{p_{-} f}}{\lambda_{f}} \frac{\partial T_{f}}{\partial t}-\frac{\partial^{2} T_{f}}{\partial x^{2}}
$$

The fluid temperature in each time - space element $\Omega_{T}^{j}$ is approximated by a linear combination of timedependent Trefftz-type basis functions $f_{j k}(x, y, t)$ :

$$
\tilde{T}_{f}^{j}(x, y, t)=\sum_{k=1}^{l w} T_{f}^{n} f_{j k}(x, y, t)
$$

where $n$ is the node number in the entire domain $\Omega_{T}$, $T_{f}^{n}$ denotes the approximate values of the fluid temperature in nodes $j, k, l w$ are defined as for Eq. (13).

The unknown temperature values at nodes $T_{f}^{n}$ were calculated by minimizing the functional, similar to this described in [16]. It represents the mean square error of the approximate solution on the boundary, in the initial time and along common edges of neighboring elements.

The set of Eqs. (2) and (5-9) was solved like in [16].

\section{Results and discussion}

The study shows the results obtained for the subcooled boiling region and the most important concern was to the heat transfer coefficient identification. The coefficient was found by solving the inverse heat conduction problem by using the FEM with time-dependent Trefftztype basis functions. The calculations were performed using two minutes time-dependent temperature measurements but only selected results - from $1 \mathrm{~s}$ to $100 \mathrm{~s}$ - were presented. This data were selected to present the results obtained for the subcooled boiling region.

The relationship between the heat transfer coefficient and the distance from the minichannel inlet, were determined for three times: $t_{10}=10 \mathrm{~s}, t_{50}=50 \mathrm{~s}$ and $t_{80}=80 \mathrm{~s}$ and shown in Fig. 4a. Figure $4 \mathrm{~b}$ presents the heat transfer coefficient vs. time calculated on the basis of temperature measurements from six selected thermocouples (T2, T5, T8, T11, T14 and T17) with the increasing heat flux being supplied to the foil. Results obtained for the points where listed above thermocouples were selected as representative for the subcooled boiling region data.

When analysing the dependence transfer coefficient vs. the distance from the minichannel inlet shown in Fig. $4 \mathrm{a}$, it can be noticed that the highest values of the heat transfer coefficient up to $1.6 \mathrm{~kW} /\left(\mathrm{m}^{2} \mathrm{~K}\right)$ are achieved near the outlet of the minichannel and the lowest are obtained at its inlet. It is worth mentioning that presented results concerns first part of experiment when the lowest heat flux was supplied to the heated foil.

The results in Fig. $4 \mathrm{~b}$ are presented as the heat transfer coefficient vs. time. The local heat transfer coefficients determined on the basis of the foil temperature measured at six selected points measured between $1 \mathrm{~s}$ and $100 \mathrm{~s}$ were shown in this graph. It was observed that local heat transfer coefficient values 
increased with increasing distance from the minichannel and achieved the highest values up to $1.6 \mathrm{~kW} /\left(\mathrm{m}^{2} \mathrm{~K}\right)$, at the minichannel outlet and the lowest were near the minichannel inlet approx. $0.2 \mathrm{~kW} /\left(\mathrm{m}^{2} \mathrm{~K}\right)$.
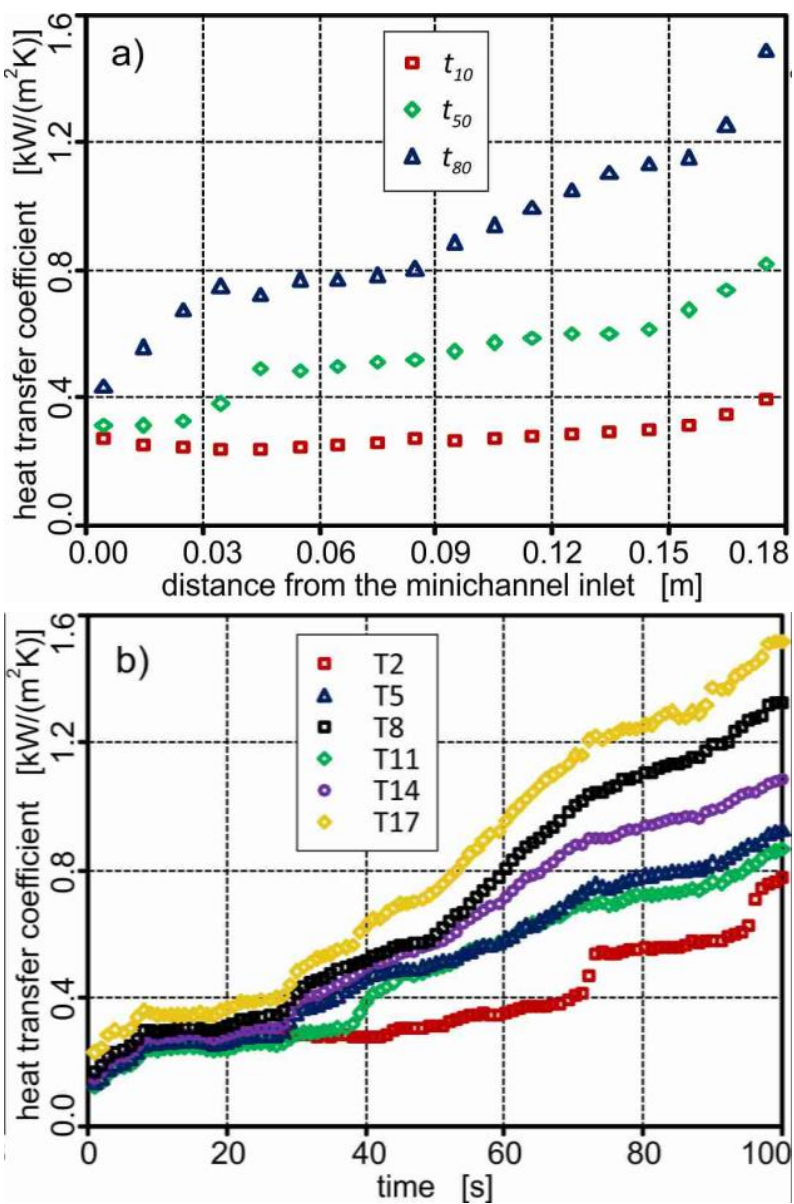

Fig. 4. Heat transfer coefficient vs.:

a) the distance from the minichannel inlet for selected time intervals : $t_{10}=10 \mathrm{~s}, t_{50}=50 \mathrm{~s}$ and $t_{80}=80 \mathrm{~s}$,

b) time calculated on the basis of temperature measurements from selected thermocouples: T2, T5, T8, T11, T14 and T17 ; experimental parameters: heat flux density from $1.8 \mathrm{~kW} / \mathrm{m}^{2}$ to $46 \mathrm{~kW} / \mathrm{m}^{2}$, average inlet pressure $122 \mathrm{kPa}$, average mass flow rate $0.012 \mathrm{~kg} / \mathrm{s}$.

\section{Conclusions}

The method of solving the time-dependent inverse heat transfer problem in flowing fluid using the FEM with time-dependent Trefftz-type basis functions were discussed in this paper. The objective of the numerical calculations, refer to an experiment, was to determine the heat transfer coefficient during FC-72 flow in an asymmetrically heated minichannel. Only results concerned subcooled boiling region was discussed The heated foil surface temperature was recorded continuously in 18 points by thermocouples. Other experimental parameters necessary for calculations were also monitored in $0.01 \mathrm{~s}$ intervals. The heat transfer coefficient, on the heated foil-fluid in the minichannel, was obtained from the Robin boundary condition. It was assumed that the nonstationary temperature distribution in the flowing fluid was described by the FourierKirchhoff equation. The unknown temperature values at nodes were computed by minimizing the functional which describes the mean square error of the approximate solution on the boundary, in the initial time and along common edges of adjacent elements. The auxiliary nonstationary temperature distribution in the heated foil, described by the heat equation, was obtained by Trefftz method. The values of the time-dependent local heat transfer coefficient were discussed. It was confirmed that under the subcooled boiling, local heat transfer coefficients achieved rather values up to $1.6 \mathrm{~kW} /\left(\mathrm{m}^{2} \mathrm{~K}\right)$, at the minichannel outlet. The lowest values of the coefficient were obtained at the minichannel inlet.

\section{References}

1. M. N. Özisi̧k, H. R. B. Orlande, Inverse heat transfer: fundamentals and applications. Fundamentals and Applications (Taylor \& Francis, New York, 2000)

2. E. Trefftz, International Kongress für Technische Mechanik (1926)

3. I. Herrera, Numer. Methods Partial Differ. Equ. 16, $6(2000)$

4. S. Y. Reutskiy, Eng. Anal. Bound. Elem. 28, 1 (2004)

5. B. Movahedian, B. Boroomand, S. Soghrati, Eng. Anal. Bound. Elem., 37 (2013)

6. S. Blasiak, A. Pawinska, Int. J. Heat Mass Transf., 90 (2015)

7. K. Grysa, A. Maciag, Int. J. Heat Mass Transf., 100 (2016)

8. K. Grysa, B. Maciejewska, J. Theor. Appl. Mech. 51, 2 (2013)

9. B. Maciejewska, J. Theor. Appl. Mech. 55, 1 (2017)

10. B. Maciejewska, M. Piasecka, Heat Mass Transf., 53 (2017)

11. B. Maciejewska, K. Strak, M. Piasecka, Int. J. Numer. Methods Heat Fluid Flow 28, 1 (2018)

12. B. Maciejewska, K. Strąk, M. Piasecka, Procedia Eng., 157 (2016)

13. M. Piasecka, K. Strąk, B. Maciejewska, Heat Transf. Eng. 38, 3 (2017)

14. S. Hożejowska, J. Theor. Appl. Mech. 53, 4 (2015)

15. M. Cialkowski, J. Therm. Sci. 11, 2 (2002)

16. B. Maciejewska, M. Piasecka, Int. J. Heat Mass Transf., 107 (2017) 